\title{
Experiences of School Belonging for Young Children With Refugee Backgrounds
}

\author{
Clemence Due, ${ }^{1}$ Damien W. Riggs ${ }^{2}$ and Martha Augoustinos ${ }^{1}$ \\ ${ }^{1}$ School of Psychology, The University of Adelaide, Australia \\ ${ }^{2}$ School of Social and Policy Studies, Flinders University, Australia
}

\begin{abstract}
Previous research with adolescents with refugee backgrounds living in countries of resettlement has found that school belonging has an impact on a range of wellbeing and developmental outcomes, including mental health, peer relationships, self-esteem and self-efficacy, and academic achievement. However, very little research has explored school belonging in younger children with refugee backgrounds (i.e., under 13 years of age). In this article we report on a participatory research project concerning the experiences and understandings of school belonging with 15 children with refugee backgrounds (aged from 5 to 13 years old) who had been living in Australia for less than 12 months. The research aimed to explore experiences of school and school belonging from the perspective of children, and utilised photo elicitation techniques. The study found that refugee children were able to create a sense of school belonging through aspects of the school environment that reflected their identity and values, and through their relationships with their peers and teachers. In conclusion, we highlight the importance of ensuring that schools create spaces for refugee students to demonstrate their knowledge, values, and skills at school, and to ensure that strategies to promote school belonging in refugee students take into account their experiences and identity.
\end{abstract}

- Keywords: refugee children, school belonging, photo elicitation, education

In 2015, the office for the United National High Commissioner for Refugees (UNHCR) reported that there were nearly 20 million refugees worldwide, over half of whom were under 18. This is the highest number of refugees since World War II (UNHCR, 2015). While only a proportion of these young people and their families will be moved to a resettlement country, it is nevertheless vitally important that resettlement countries have an evidence base upon which to draw when providing settlement services and support to young people with refugee backgrounds.

In resettlement countries such as Australia, school is one of the primary places where newly arrived refugee students will connect with their community, build relationships, and establish a sense of belonging in their new country (Correa-Velez, Gifford, \& Barnett, 2010; de Heer, Due, \& Riggs, 2016; Mace, Mulheron, Jones, \& Cherian, 2014; Matthews, 2008; Woods, 2009). As such, school belonging plays a crucial role in establishing a sense of social inclusion, positive wellbeing, and the development of

Address for correspondence: Clemence Due, School of Psychology, Level 4, Hughes Building, The University of Adelaide SA 5005, Australia. Email: clemence.due@adelaide.edu.au. 
peer relationships for refugee young people from the beginning of their resettlement (Correa-Velez et al., 2010; de Heer et al., 2016; Woods, 2009).

However, while there is a body of research that has explored school belonging in adolescents in general (Anderman, 2002; Goodenow, 1993; Shochet \& Smith 2014; Van Ryzin, Gravely, \& Roseth, 2006), and in adolescents with refugee backgrounds in particular (Gifford, Correa-Velez, \& Sampson, 2009; Kia-Keating \& Ellis, 2007; Trickett $\&$ Birman, 2005), very little research has explored experiences of school belonging for young people (aged under 13) with refugee backgrounds. As such, the aim of the current article was to consider experiences of school belonging in a sample of young students with refugee backgrounds in Intensive English Language Centres (IELCs) in South Australia. In considering these experiences, the study also aimed to explore the role of schools in providing support to newly arrived refugee young people and their families.

\section{School Belonging}

School belonging is typically defined as a multidimensional concept, incorporating a student's level of attachment, commitment, involvement, and belief in their school (Wehlage, Rutter, Smith, Lesko, \& Fernandez, 1989). As such, definitions of school belonging mirror definitions of belonging more broadly (e.g., Baumeister \& Leary, 1995). Specifically, attachment to school refers to attachment to the broader school and students' investment in the school itself, including in relation to both environmental aspects and interpersonal relationships (Baumeister \& Leary, 1995; Goodenow, 1993). Commitment refers to issues such as how happy students are to comply with the rules and expectations of their school, and has been shown to influence decisions about school in adolescents, such as whether to remain at school or leave. Involvement at school includes a focus on student engagement (both in relation to academic work, as well as any extracurricular activities that are school related). Finally, belief in school refers to the extent to which students feel that their school values have significance for them. Taken together, higher levels of school belonging have been shown to be related to a number of positive outcomes for adolescents, including improved self-esteem and motivation, and lower levels of depression and peer rejection (Anderman, 2002; Battistich, Solomon, Watson, \& Schaps, 1997; Goodenow, 1993; Kia-Keating \& Ellis, 2007; Sujoldzic, Peternel, Kulenovic, \& Terzic, 2006).

Correspondingly, understanding experiences of school belonging in students from refugee backgrounds is critically important. Indeed, ensuring that schools and other educational institutions understand how to promote school belonging for refugee students is vital to providing students with the opportunity to feel a sense of connection to their school environment (Kia-Keating \& Ellis, 2007). Moreover, such an understanding must take into account refugee students' own identities and knowledge, rather than assuming that refugee students can simply 'fit in' to existing school environments and school cultures (Matthews, 2008; Woods, 2009). In other words, understandings of school belonging for students with refugee backgrounds must lead to a two-way interaction that takes into account existing power relationships and ensures that refugee students can feel belonging in all of the domains on their own terms as well as those of the school (Matthews, 2008; Riggs \& Due, 2011; Woods, 2009).

Despite the importance of focusing on belonging for refugee students, there is currently very little research outlining how such students experience school belonging 
in resettlement countries such as Australia, with most of the educational literature focusing on either English language acquisition (e.g., Oliff \& Couch 2005), social inclusion (e.g., Block, Cross, Riggs, \& Gibbs, 2014; de Heer et al., 2016), issues of social justice (e.g, Keddie, 2012; Taylor \& Sidhu, 2012), or promoting whole-school approaches (e.g., Pugh, Every, \& Hattam, 2012). While each of these areas is important, our aim in this article is to provide an overview of how refugee students experience school belonging specifically, and to consider how these experiences can be used in policies for refugee education in resettlement countries.

\section{School Belonging in Refugee Students}

Kia-Keating and Ellis (2007) argue that schools have a 'unique and influential impact on the lives of adolescents' (p. 30), and that this impact is particularly important for newly arrived refugee students as they learn to navigate their new environments. In their study of 76 Somalian refugees aged between 12 and 19 in the United States, KiaKeating and Ellis found that higher levels of school belonging were related to lower levels of depression and higher levels of self-efficacy, reflecting the broader studies noted above. Importantly, Kia-Keating and Ellis note that studies considering the experiences of refugee students at school - and the impact of these experiences on school belonging - are important given the relationship between school belonging and some wellbeing domains. The protective role of school belonging in relation to positive wellbeing outcomes has also been found in other studies (e.g., Fazel, Reed, Panter-Brick, \& Stein, 2012; Rousseau, Drapeau, \& Platt, 2004; Sujoldzic et al., 2006).

In a second study undertaken in the United States, Trickett and Birman (2005) found a positive relationship between overall support at school and school belonging in a sample of 110 adolescents with refugee backgrounds from the former Soviet Union. Interestingly, they found different results for support from American peers as compared to support from Russian peers, and conclude that ' ... substantively, these findings suggest the importance of ethnic peer support in creating an alternative sense of belonging for adolescents who did not feel that they fit into the school' (p. 36). In other words, they found that while support from American peers was positively related to school belonging, not all students experienced this support. When this support was not available, support from Russian peers provided an important avenue for experiencing belonging. However, Trickett and Birman found that Russian peer support was related to higher levels of disciplinary infraction in their sample of refugee students, although they did not explore the extent to which this was due to the fact that students who felt they did not 'fit in' at school may be more likely to behave in ways perceived to be outside the rules of the school. They also found a positive relationship between parental support and school belonging, highlighting the importance of involving parents in the school community in addition to students.

In the Australian context, the Good Starts study (Gifford et al., 2009) found that school belonging was an important factor in the wellbeing of newly arrived adolescents with refugee backgrounds (aged 12-18 years) enrolled in English language schools (ELS) in Melbourne. Gifford et al. (2009) found that the students in their study valued their time at school and had high aspirations in relation to their education. Specifically, their findings indicate that students reported valuing, among other things, the cultural diversity of their intensive language school, the presence of other students who spoke their own language, having a sense of safety and belonging, and a curriculum that allowed them to experience some success in their education. These findings indicate 
the importance of ensuring that the facilitation of school belonging is collaborative and reciprocal, by providing opportunities for refugee students to contribute their own knowledge and aspirations, rather than focusing school experiences on existing school values and culture (Matthews, 2008; Woods, 2009).

Finally, the literature exploring school belonging for refugee students has also found that school belonging is negatively affected by experiences of discrimination (e.g., Brown \& Chu, 2012; Trickett \& Birman, 2005). Specifically, experiences of discrimination lead to a range of negative outcomes, including difficulties developing peer relationships at school, lower levels of school belonging and engagement, and decreased mental health and wellbeing (Priest et al., 2014).

Taken together, these findings indicate that, as with young people in general, school belonging plays an important role in a range of areas of young people with refugee backgrounds, including mental health and wellbeing. In addition, it is important to note that positive experiences of school belonging play a particularly important role for young refugee students not only because of the outcomes of school belonging outlined above, but also because trauma and mental health interventions for refugees are increasingly being administered through schools (Ehntholt \& Yule, 2006). It is plausible to suggest that if levels of school belonging are not high, such interventions risk being less effective from the very beginning. As such, understanding how to promote school belonging in refugee students is vitally important to their health and wellbeing in a broad range of areas.

\section{Method}

This article, with its focus on school belonging in refugee students, forms part of a broader project that aimed to explore experiences of education for students from both migrant and refugee backgrounds in South Australia. Some details of this broader study are provided in this section by way of providing contextual information to the current study.

\section{Setting}

In South Australia, the Intensive English Language Program (IELP) involves 15 Intensive English Language Centres (IELCs), located at the same sites as mainstream government-run primary schools. As such, newly arrived children - including both those with refugee backgrounds and those with migrant backgrounds - begin their education on a mainstream education site, but spend their time in specialised intensive English language classes. Students are typically enrolled in an IELC for 6 to 12 months (with special provisions for refugee students, who are eligible for extended time in the program), whereupon they transition from their IELC into mainstream education, either at the same school or at a different site (Department for Education and Child Development, 2012). Students enter the program on a continuous, rolling basis soon after their arrival in Australia rather than only in one intake at the beginning of the school year. Students are eligible to be enrolled in an IELC if they have been in Australia for less than 12 months.

It should be noted that this system of the provision of education for students with refugee backgrounds at primary school level differs around Australia, with some states enrolling students into intensive English programs that are not at the same site as 'mainstream' primary schools. In South Australia, the sites are relatively consistent 
in their approach to education and their support for transition into mainstream classes or schools; however, it should be noted that the sites do differ somewhat in the composition of the class - that is, some sites will have higher numbers of students with refugee backgrounds, and others will have higher numbers of students with migrant backgrounds.

\section{Participants}

The sample included in the broader study consisted of 63 children (15 with refugee backgrounds, and 48 with migrant backgrounds) from three separate schools with IELCs. This article focuses on the 15 children with refugee backgrounds. This sample of children was aged between 5 and 13, with seven male and eight female participants. Participants came from eight countries of origin: the Democratic Republic of the Congo, Iraq, Mongolia, Nepal, Pakistan, Papua New Guinea, Syria, and Zambia. Many spoke multiple languages, reflecting a number of moves prior to coming to Australia. The three sites under consideration were close (within $15 \mathrm{~km}$ ) over the city centre.

\section{Procedure}

Ethics approval was granted by The University of Adelaide's Human Research Ethics Committee and the Department for Education and Child Development (DECD) in South Australia. It is important to note that the authors are aware of the ethical issues of working with this vulnerable group of young people, including issues such as gaining ongoing assent from children in addition to informed consent from parents and caregivers (Due, Riggs, \& Augoustinos, 2014; Gifford, Bakopanos, Kaplan, \& Correa-Velez, 2007; Crivello, Camfield, \& Woodhead, 2009). As such, the first author (who undertook the data collection) spent a term at each school involved in the study in order to build rapport with participants, to let them know about the aims of the study, and to gain ongoing assent from them for their participation (see Crivello et al., 2009; Due et al., 2014; Gifford et al., 2007).

In terms of participant recruitment, information sheets and consent forms (translated into first languages) were sent home to the parents or caregivers of most students with refugee backgrounds enrolled in the IELC. On two occasions, teachers chose not to send home information sheets and consent forms due to high levels of trauma in families who were very newly arrived.

The data collection relevant to this article consisted of a photo-elicitation methodology, with accompanying interviews. Photo elicitation, or PhotoVoice, is a research technique that has been identified as a child-focused, flexible approach to research that allows children's views to be communicated on their own terms in the research process (Darbyshire, MacDougall, \& Schiller, 2005; Due et al., 2014; Newman, Woodcock, \& Dunham, 2006). Photo elicitation involves participants being provided with a camera (in this case, a digital camera) and asked to take photos according to a particular theme that relates to the research aims.

For the purposes of our research, students were asked to take photographs that represented their experiences at school. The students were then shown their photographs on a laptop and invited to discuss their images in either a focus group of up to three children or in an individual interview. Whether discussions took place in focus groups or individual interviews was determined by external factors, such as what was happening in the classroom at the time, whether or not an interpreter 
was needed, and ensuring that the discussion did not disrupt the child's lessons. All discussion took place at the child's school. Focus groups and interviews relating to the photographs were audio recorded and transcribed, with student's names changed for anonymity.

\section{Analytic Approach}

Given that the aim of this paper was to explore experiences of school belonging, a deductive thematic analysis of the interviews and focus groups where the photographs were discussed was undertaken. Specifically, the six stages outlined by Braun and Clarke (2013) were used, including: reading and familiarisation, coding, searching for themes, reviewing themes and producing a thematic map, naming and defining themes, and finalising the analysis through writing. The final thematic structure received consensus from all authors. The final themes are presented here - under each of the areas of school belonging - together with accompanying photographs. In all instances, attempts have been made to provide representative photographs; however, due to ethical reasons, we cannot provide photographs that identify either individuals or specific schools.

\section{Results}

The themes are presented here under each of the main domains of school belonging identified in previous research (e.g., Goodenow, 1993; Kia-Keating \& Ellis, 2007; Wehlage et al., 1989). In particular, the Kia-Keating and Ellis domains are used as a deductive framework due to the fact that they have been used previously in research with students with refugee backgrounds and found to be a useful framework for school belonging (Kia-Kating \& Ellis, 2007). Three themes were seen under the domain of attachment (Specific spaces and activities in the school help build school attachment; Friendships with children from similar cultural, ethnic or linguistic backgrounds help build attachments to the school; and Relationships with teachers help build attachments to the school), two under the domain of commitment (Commitment to the school is seen through school rules and The requirement to learn English may impact school commitment), one under involvement (Involvement in the school is seen through school activities, not extracurricular activities), and one under belief (Students believe in their school when it reflects their identities and values). These are outlined further below.

\section{Attachment to the School}

The domain of attachment to school refers to personal investment in the school, and attachment to the school community and space (e.g., Kia-Keating \& Ellis, 2007; Goodenow, 1993; Wehlage et al., 1989). In general, students displayed high levels of attachment to their school and indicated that they enjoyed coming to school and participating in school activities. Specific ways in which students created or displayed this attachment are discussed in this section, under the subheadings below.

Specific spaces and activities in the school help build school attachment. Attachment to the school was often displayed through students' attachment to spaces in the school grounds, leading to investment in particular aspects of school life (defined by 


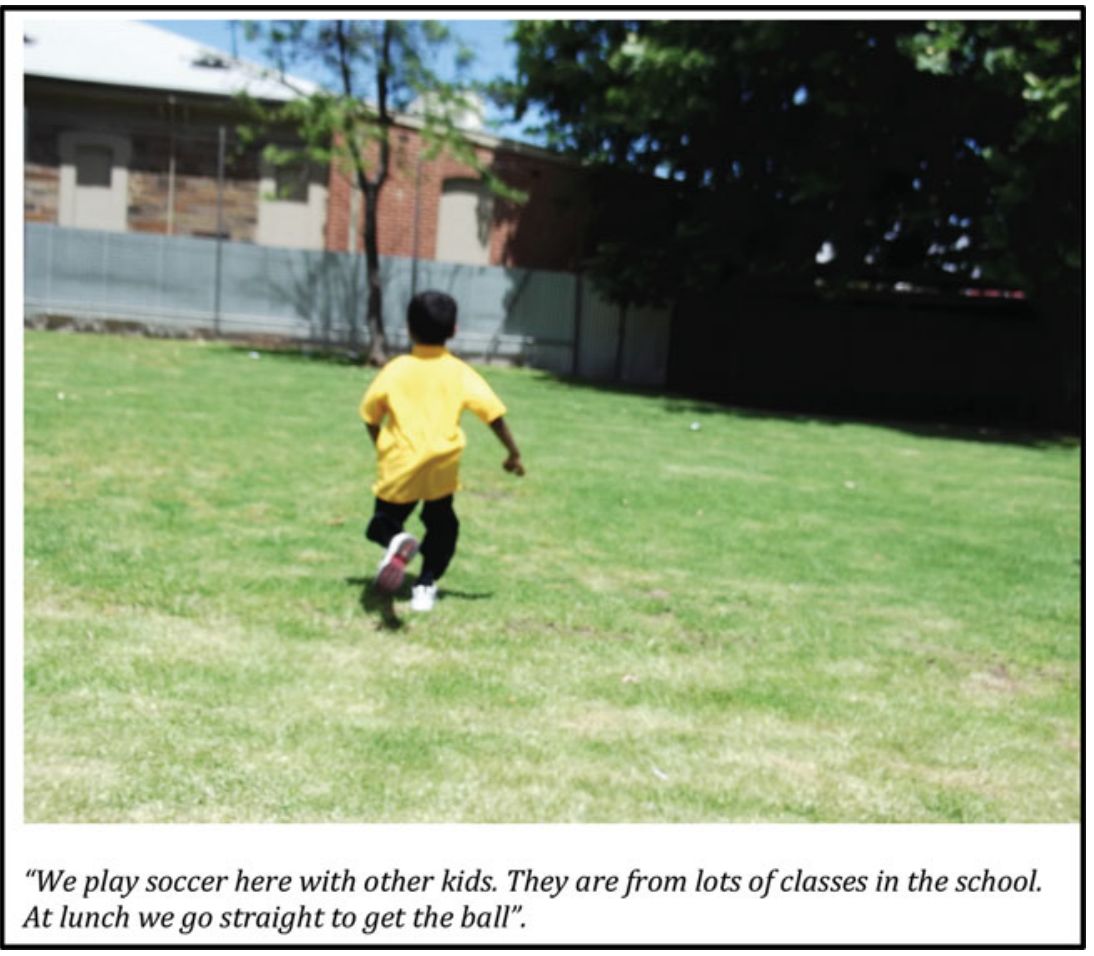

\section{FIGURE 1}

A child running on an oval.

particular spaces). These spaces were generally places where students frequently went for their classes (such as their own classroom, the school library, the school gym, or the art room), but also included playground spaces where the students typically spent their breaks. It is noteworthy that, as found in previous research (de Heer et al., 2016), such spaces and activities frequently revolved around activities that did not rely on knowledge of English, such as art and sport. Indeed, all of the 15 students in this study photographed spaces in the school that involved learning in areas that did not rely on English. Examples of photographs and extracts are seen in Figures 1, 2 and 3.

As the photographs and excerpts in Figures 1,2 and 3 indicate, students frequently drew upon spaces or activities that did not rely on English language skills. Indeed, in the last excerpt, the students discussing the photograph either actively avoided, or were excluded from, activities that did rely specifically on English language competency (i.e., sitting and talking). Correspondingly, the students often spoke about forming friendships specifically with students with whom they could identify, and this is discussed in the following section.

Friendships with children from similar cultural, ethnic, or linguistic backgrounds help build attachments to the school. The children frequently took photographs of their friends and discussed their peer relationships. Indeed, as in the previous theme, all students photographed other students, and stated in interviews that this was because they were their friends. When asked why particular children in photographs were their 


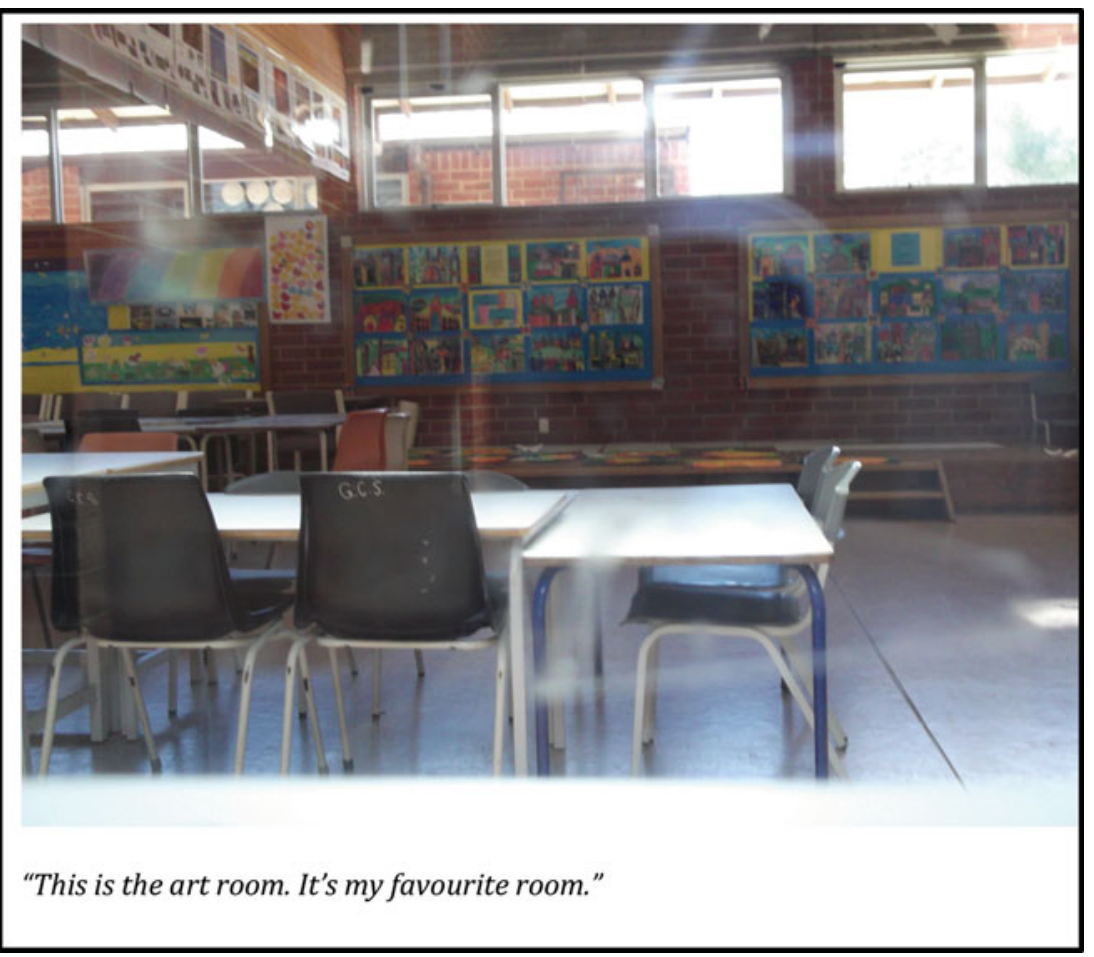

FIGURE 2

Inside an art room.

friends, 10 of the 15 the students indicated that they sought friendships with children from similar cultural, ethnic or linguistic backgrounds to themselves, and that these relationships increased their sense of school belonging. Examples of photographs and excerpts discussing friendships can be seen in Figures 4 and 5.

Relationships with teachers help build attachments to the school. All the students in the study discussed their relationship with their teachers, and it is notable that all students took photographs of at least one of their teachers (usually either their classroom teacher or a school support officer). An example of this type of photograph is seen in Figure 6.

Students displayed excitement when talking about their teachers, generally indicating that their sense of school belonging was improved by these relationships. Again, this supports previous research concerning the importance of relationships with teachers (Crouch, Keys, \& McMahon, 2014) and is elaborated further in the Discussion section.

\section{Commitment the School}

The school commitment domain of school belonging refers to areas such as valuing and adhering to school rules and expectations (e.g., Kia-Keating \& Ellis, 2007; Goodenow, 1993; Wehlage et al., 1989). Commitment to the school was less evident in the photographs than the previous domain of attachment to school. However, it is 


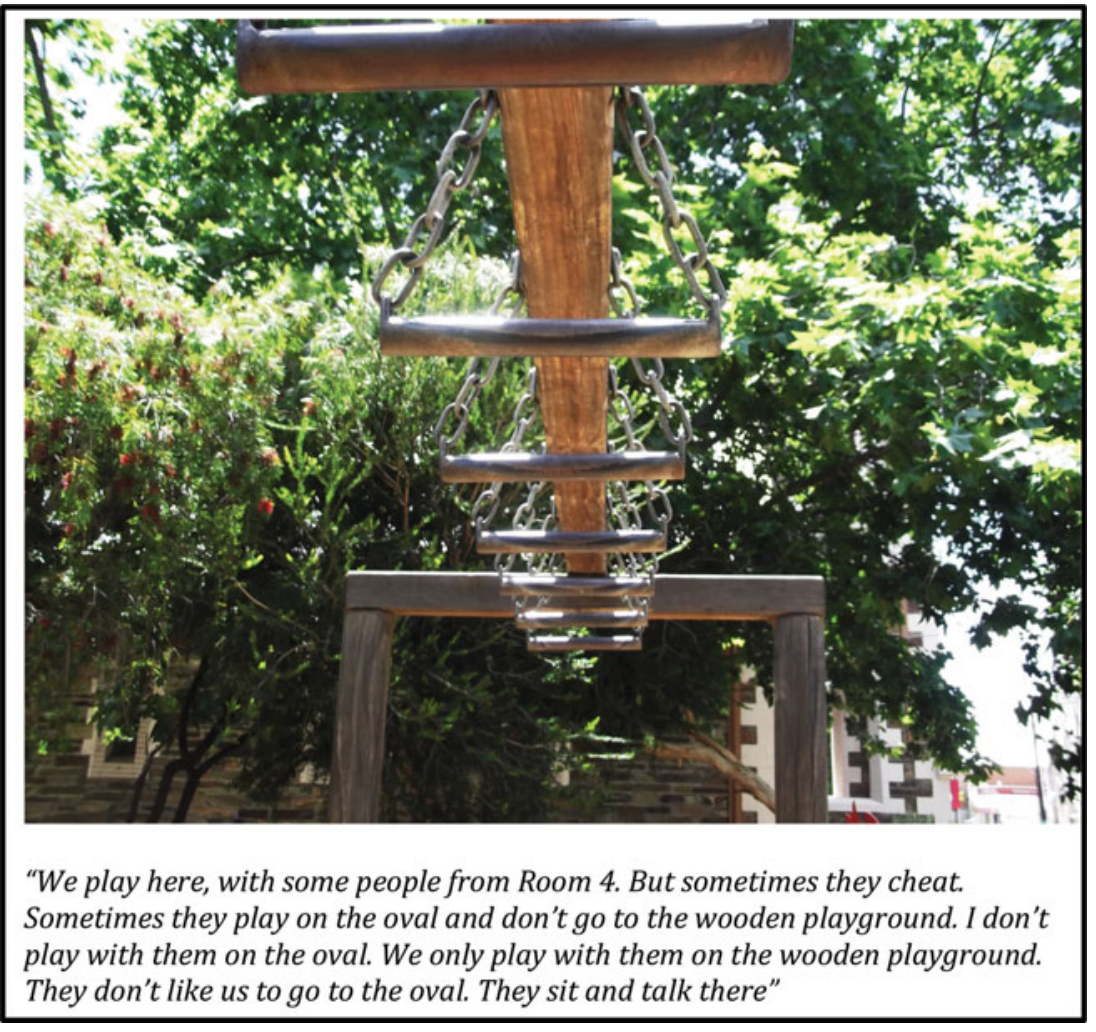

FIGURE 3

A playground.

worth noting that the fact that students took so many photographs of their teachers, as discussed above, could indicate an element of commitment to the school in terms of their enjoyment of participating at school.

Commitment to the school is seen through school rules. Students did sometimes discuss school rules in the photograph, with 4 of the 15 students noting at least one school rule or expectation in their interviews. These rules of expectations were typically discussed in relation to certain areas of the school grounds that were 'out of bounds', as seen in Figure 7. Here, a student outlines a place in the schoolyard where the students are not meant to play alone. However, photographs and discussions such as this were rare, and this photograph illustrates one of the few times when students discussed school rules in this research.

The Requirement to Learn English May Impact School Commitment

Notably, commitment to the school also came up in relation to learning English and the expectation that students were at school in order to learn English, first and foremost. Indeed, eight of the students in this study discussed English in their interviews. An example of this is shown in Figure 8. 


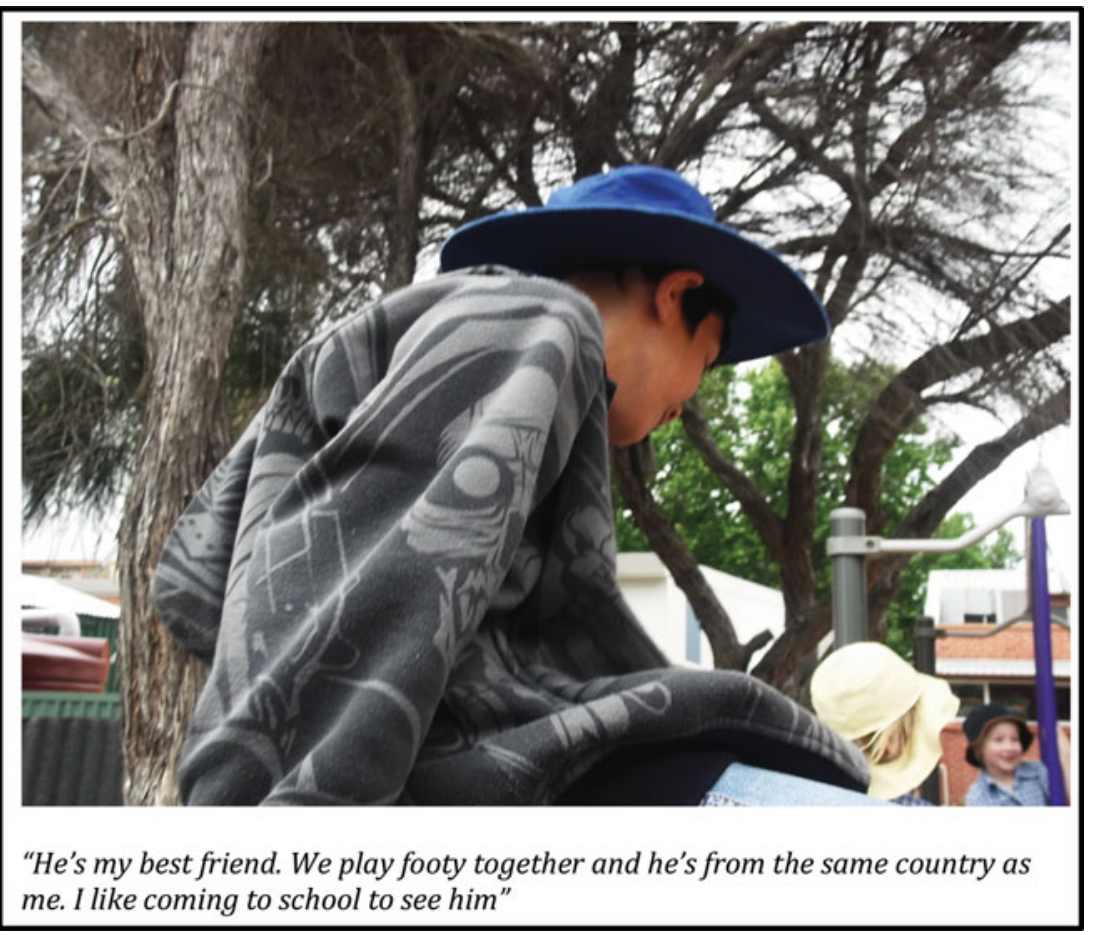

\section{FIGURE 4}

A friend sitting on some play equipment.

The extract seen in Figure 8 indicates the impact of the focus on learning English on school belonging for the students - in particular, the fact that speaking English was seen as an important element of the school's identity, and that not wishing to speak English was likely to lead to a dislike of school in Australia. This is perhaps particularly noticeable in the students' expression of 'this school' rather than school in general, suggesting that the student may otherwise have a positive relationship with school and education.

Involvement in the School

The domain of involvement in the school generally concerns both students' engagement with their academic work, as well as their involvement in schoolrelated extracurricular activities (Kia-Keating \& Ellis, 2007; Wehlage et al., 1989). While students showed high levels of engagement with their academic work, they did not appear to be involved in many extracurricular activities associated with the school. In this domain, all of the students in the study took photographs inside their classrooms and displayed high levels of engagement with their academic work at the school, leading to the theme 'Involvement in the school is seen through school activities, not extracurricular activities' (see Figures 9 and 10).

While students displayed high levels of engagement with school activities conducted during school hours, very few students were engaged with extracurricular activities 


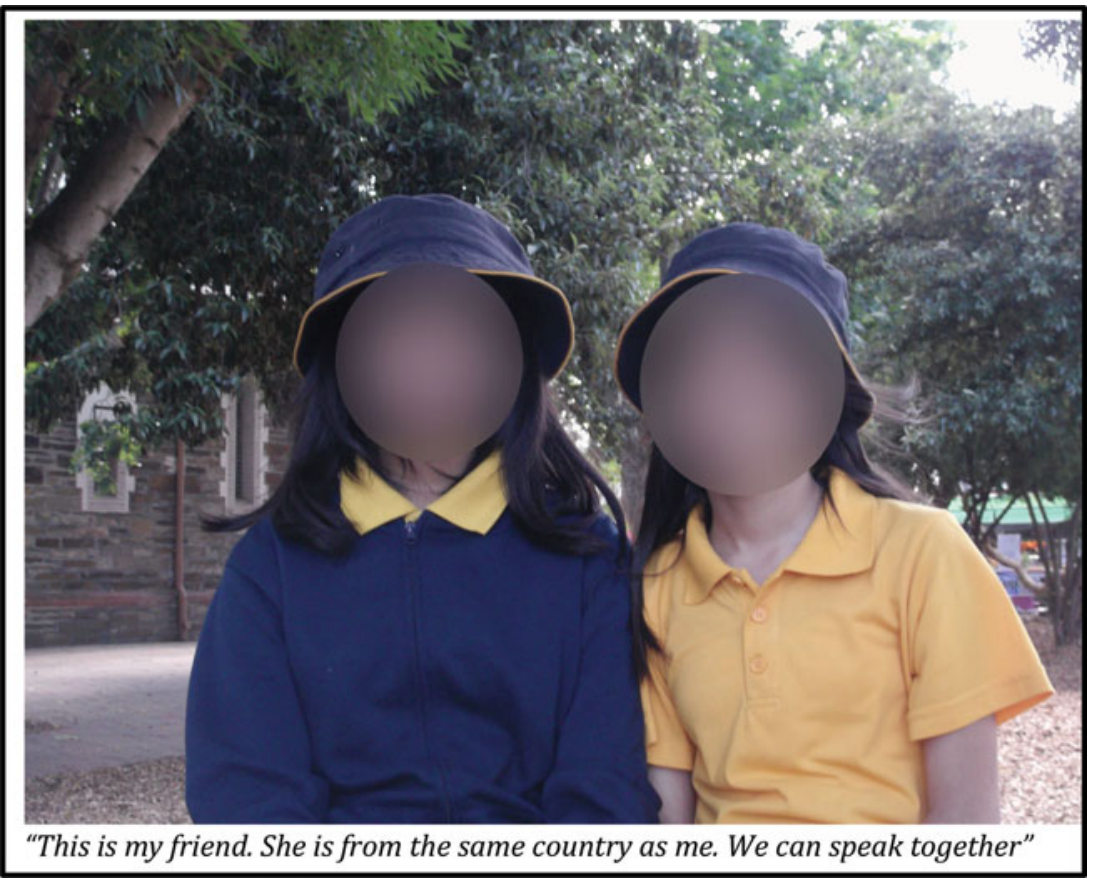

FIGURE 5

Two friends sitting together.

outside school. This could be indicative of their newly arrived status (in that they had not had the opportunity to engage with activities out of school as yet), but it could also indicate an issue for this group of students in relation to school belonging. Indeed, only one student discussed participating in extracurricular activities related to the school (in this case, attending a sport session on the weekend). It is worth noting that this was not due to students simply not talking about activities outside school, since other students discussed their weekend or after-school activities, including religious events, language school, and seeing family. Again, this is a point we take up further in the Discussion section.

\section{Belief in the School}

The domain of belief in the school refers to a sense of loyalty to the school and its values (Kia-Keating \& Ellis, 2007). Students displayed a quite high degree of loyalty to some aspects of their school, most noticeably in relation to their IELC. Ten of the 15 students discussed their IELC as being very important to their sense of belonging in school since the IELC reflected the diversity of the students in the classroom, leading to the theme 'Students believe in their school when it reflects their identities and values'. In particular, students frequently took photographs of school spaces that reflected their experiences as refugees and told us that they felt that these spaces reflected their own identities in ways that 'mainstream' classrooms did not. Figures 11, 12 and 13 provide examples of these photographs. 


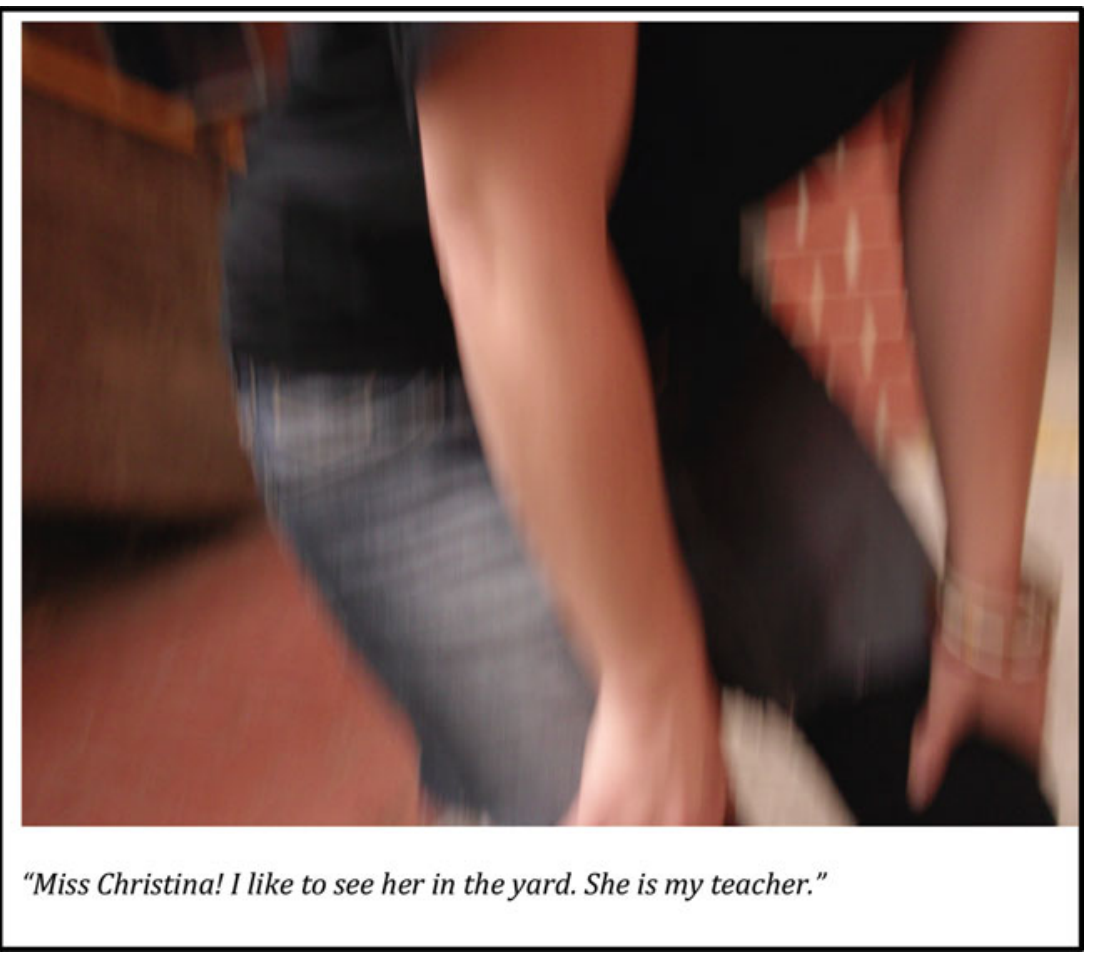

\section{FIGURE 6}

A classroom teacher.

As can be seen in the excerpt relating to Figure 11, the students frequently articulated that they valued aspects of the school that reflected some of their experiences as refugees. Here the student states that the poster 'tells other people about things for me', with the implication that there were challenges explaining these experiences to other students in the school at other times. It is plausible that the poster allowed the student to see how the values of the school aligned with her own experiences, thereby increasing school belonging. In this sense, posters such as this one and the one displayed in Figure 12 may play an important role in that they reflect refugee students' experiences and identities in the school, rather than reflecting only non-refugee or 'mainstream' identities.

Apart from posters reflecting values consistent with their experiences and identities, refugee students also discussed some activities as consistent with their own values. Earlier, we noted that subjects that do not rely on English, such as art and sport, were important for attachment to school. Here, students discuss other school activities as reflecting the activities that they enjoyed and had participated in prior to coming to Australia. An example of this is seen in Figure 13. Here, the student discusses how participating in a school activity — planting - reminded her of her country prior to coming to Australia and that she enjoyed the activity for this reason. Again, this indicates the importance of ensuring that school activities also reflect the identities and values of students from refugee backgrounds, and incorporates these into school curriculum and daily activities. 


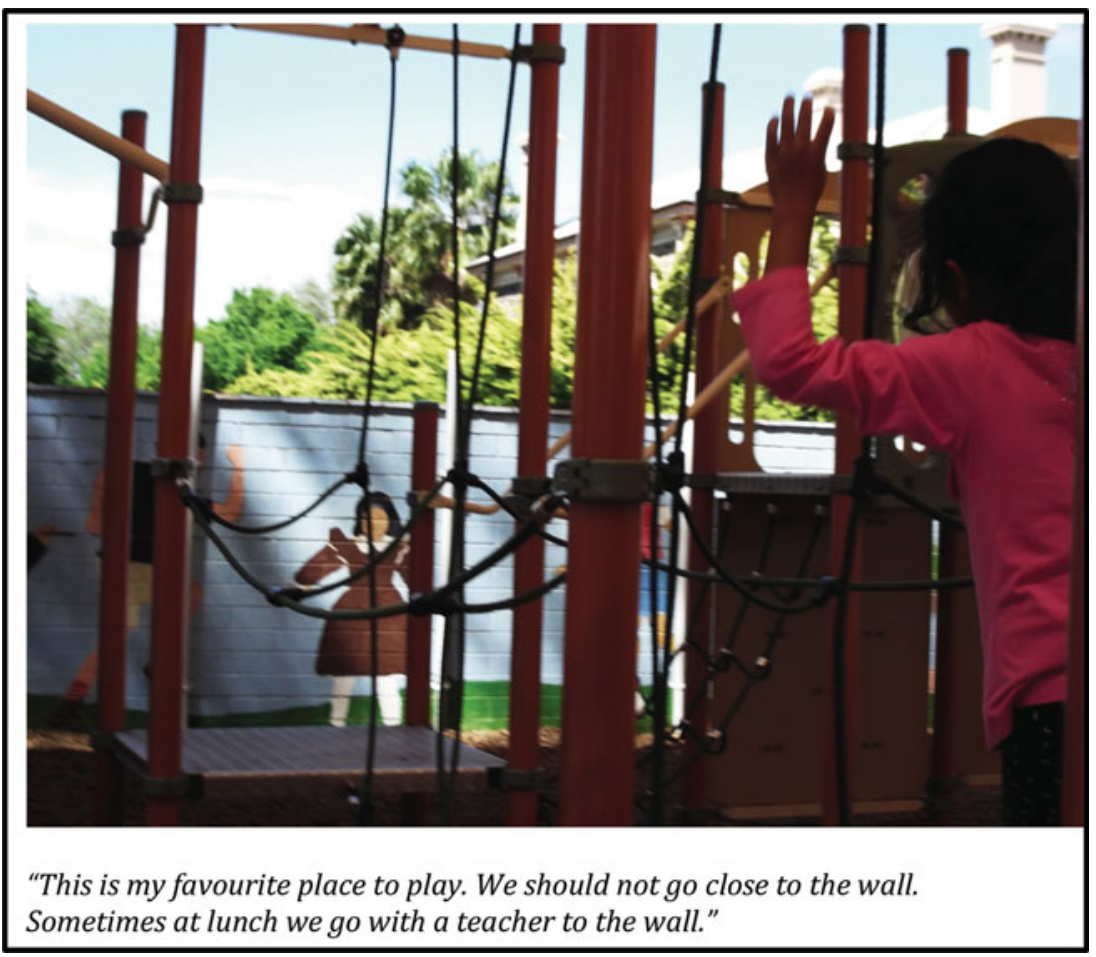

FIGURE 7

Some play equipment near an "out of bounds" area.

\section{Discussion}

One of the most important findings of the present study relates to the fact that the refugee students appeared to forge their own sense of school belonging in ways that may differ from that of other groups of students. This was particularly seen in relation to the domain of 'belief in the school', whereby students discussed how important posters and activities depicting refugee-like experiences were to their sense of belonging at school. This finding is important since previous research indicates that school belonging is likely to be improved when students see themselves and their families reflected in the beliefs of the school, and this may be difficult for students newly arrived to Australia (Block et al., 2014; Kia-Keating \& Ellis, 2006). In this sense, the IELCs included in this study appeared to offer students some reflection of their experiences as refugees (as seen in this article, by promoting organisations such as the UNHCR and initiatives such as World Refugee Day).

However, it is important to note that such a reflection may not carry through to mainstream classes, and that studies which investigate school belonging in children outside IELCs are therefore important (de Heer et al., 2016). It is also of note that while students identified some aspects of the school as consistent with their beliefs, they rarely discussed aspects of the broader school environment that may lead to a wider sense of school belonging - that is, a sense of belonging in the whole school rather than only the IELC. For example, students did not discuss areas such as the broader 


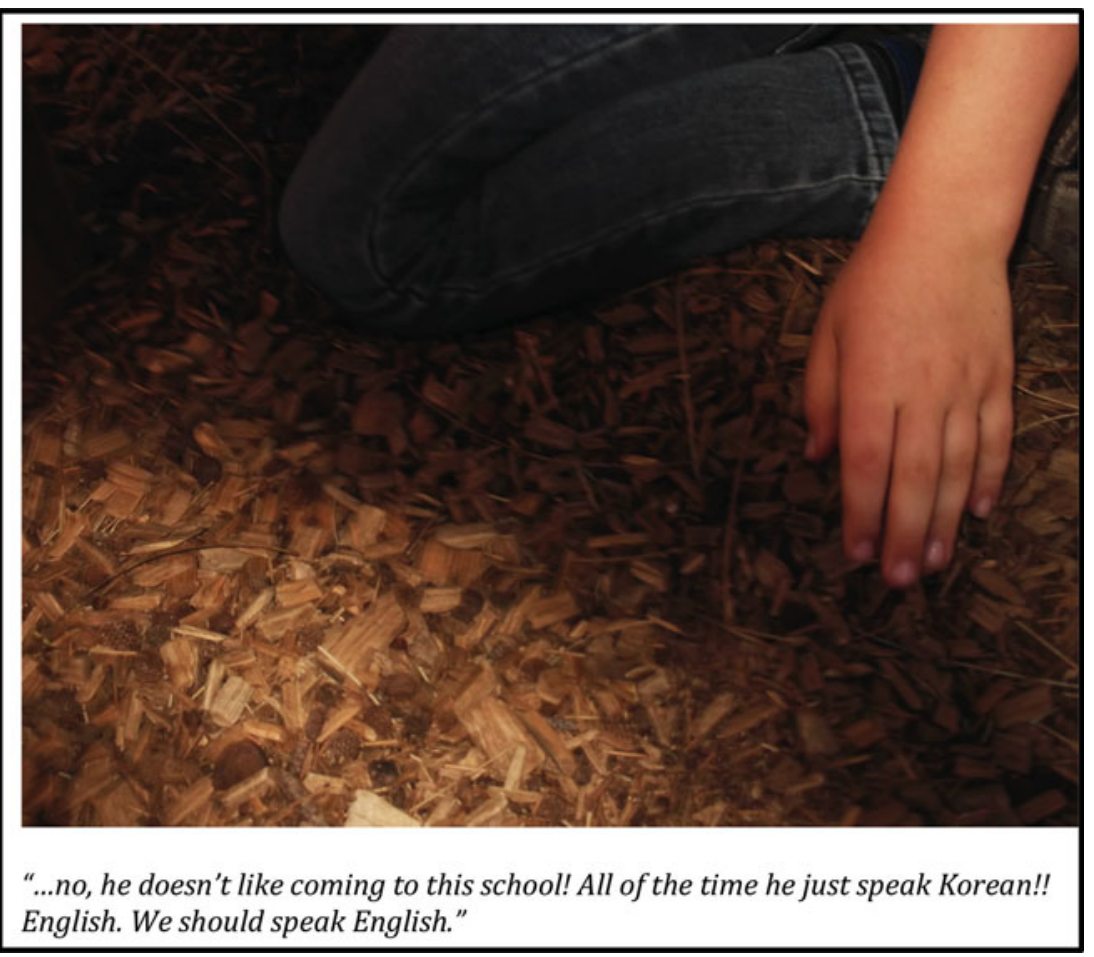

FIGURE 8

A friend sitting near some play equipment.

values of the school, or initiatives such as sports day. Again, it is beyond the scope of this study to ascertain whether this reflects the students' status as newly arrived (and therefore still forging a connection to and understanding of the schools' values), or whether this represents a limited sense of belonging in this domain.

As noted above, attachment to the school appeared to be high among the students. In terms of building school attachment, the study found that students frequently drew upon particular spaces to increase their sense of belonging at school, and discussed their relationships with teachers and peers. The finding concerning the importance of spaces reflects the findings of previous research (e.g., Due \& Riggs, 2011) and highlights the importance of ensuring that students with refugee backgrounds feel they belong in all aspects of the school and not just areas where English language is not a priority (Matthews, 2008; Trickett \& Birman, 2005; Woods, 2009). The finding concerning teachers is particularly important, given the fact that previous research highlights that good student-teacher relationships predict a range of positive outcomes, including ongoing school engagement and belonging (Crouch et al., 2014). Here, we would suggest that the fact that teaching staff in all three schools in the study were experienced in teaching students with refugee and migrant backgrounds played an important role in ensuring cultural competency and the ability to build relationships with refugee students. Our study also demonstrates that refugee students were keen to develop relationships with teachers, and that this is one useful way of immediately building school belonging when students arrive at a school in their resettlement country. 


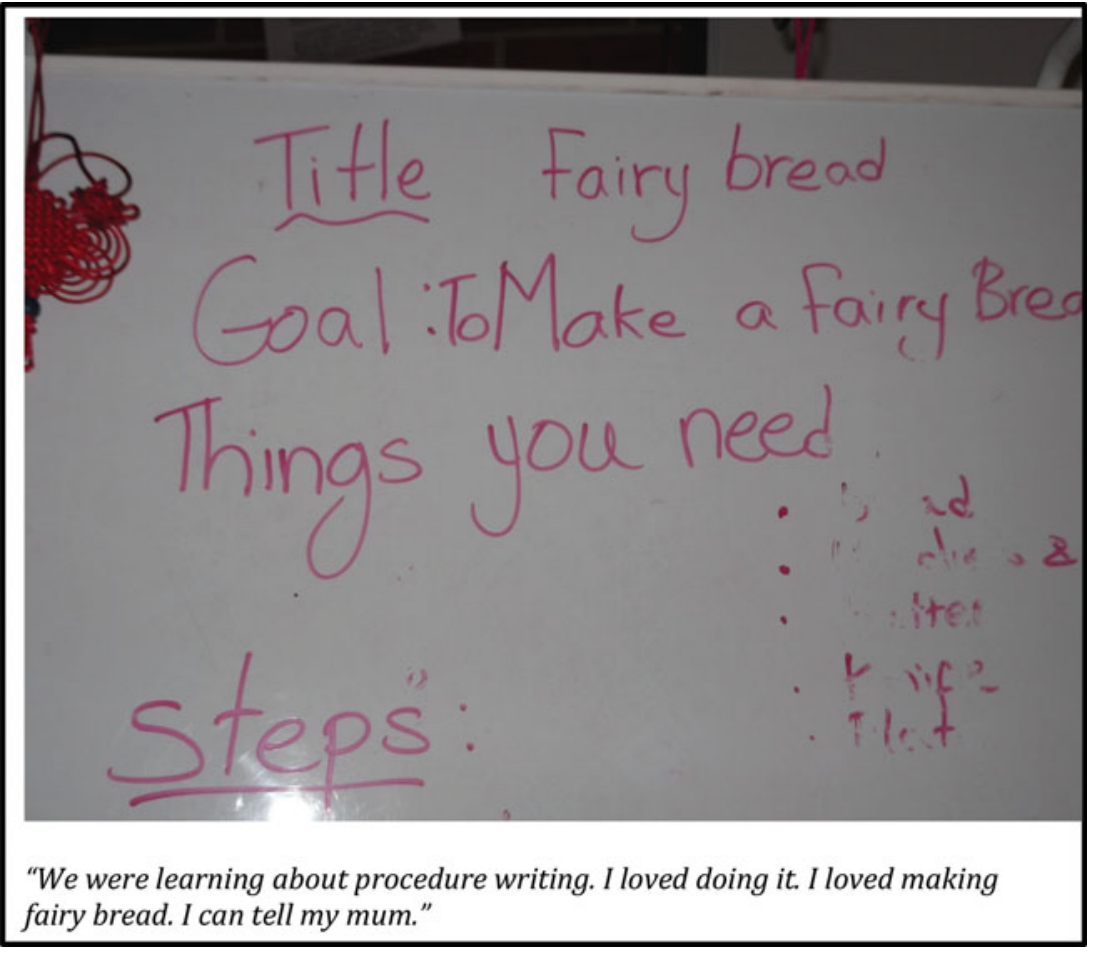

FIGURE 9

A classroom activity for learning English.

While students showed high levels of attachment to the school (or at least their IELC), the photographs taken by students did not highlight high levels of commitment or involvement in the school. In relation to commitment to the school, and as noted above, students rarely discussed school rules, although one student did note that the requirement to speak English was problematic for some students. We acknowledge here that our findings here may reflect limitations with the photo elicitation approach, in that it may have been difficult for students to capture this domain of school belonging through photographs. As such, the fact that students did not discuss school rules or other aspects of school commitment may not in fact reflect low levels of school belonging on this domain, perhaps with the exception of the potential challenge of being required to speak in English. This exception is noteworthy, however, and relates to the findings of previous research in regard to the potentially detrimental impact that a strict focus on English-language acquisition may have on refugee students at school (Matthews, 2008; Woods, 2009).

In relation to involvement at school, students displayed high levels of involvement in the academic aspect of school, and displayed high levels of educational aspiration, supporting the work of Gifford and colleagues (2009). However, only one student discussed participating in extra-curricular activities related to school. This finding is important due to previous research highlighting that elements of school belonging may be increased where participation in extra-curricular activities is higher (McNeely, Nonnemaker, \& Blum, 2002). As noted above, our findings may reflect students' 


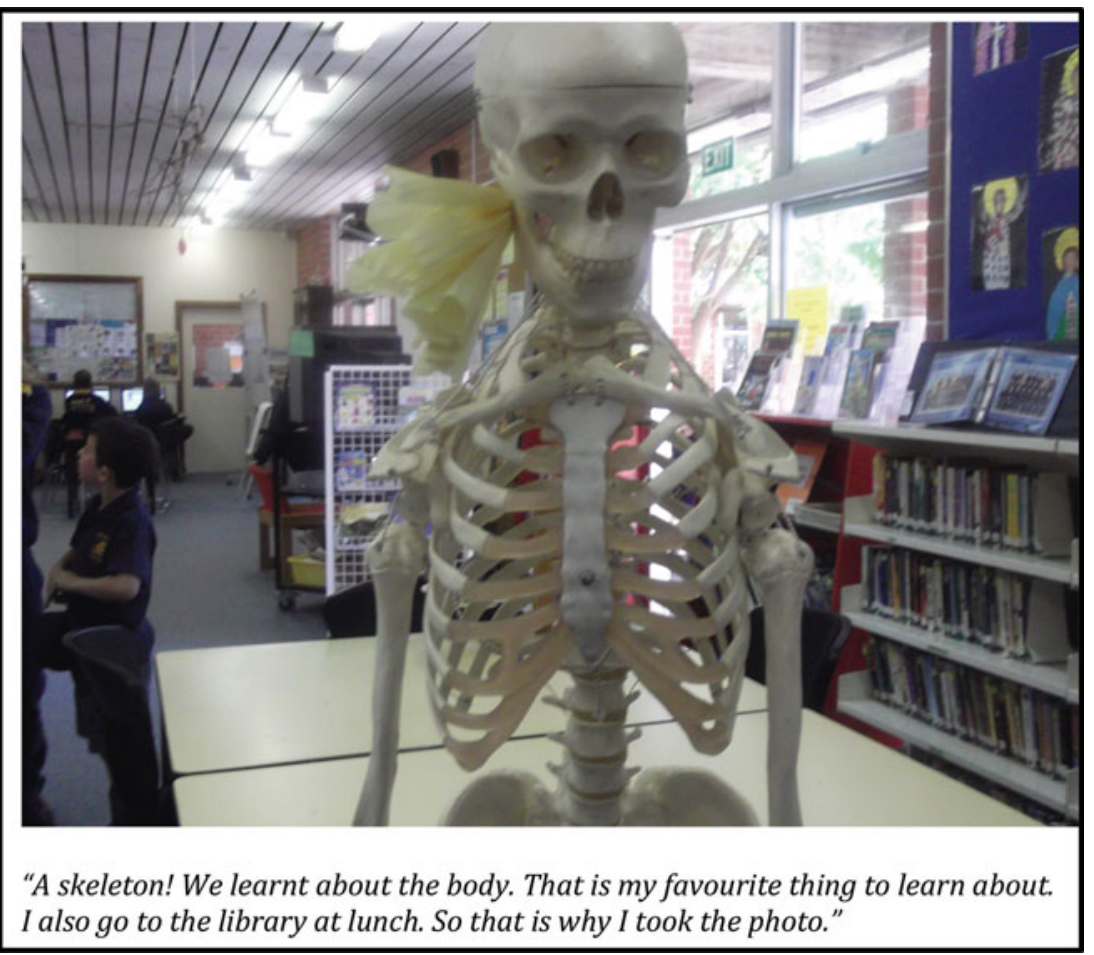

FIGURE 10

Inside a library.

newly arrived status; however, it is worth noting that increasing the ability of refugee students and their families to participate in such activities may play an important role in increase school belonging. We would also suggest that expanding the school's extracurricular activities to include events important to refugee students and their families would offer a very useful pathway for schools to assist students to develop a strong sense of school belonging. In this sense, schools could invest more time identifying activities that young people or children with refugee backgrounds may be interested in. Examples of such activities include the school hosting culturally important festivals on the weekend, holding activities for days such as Harmony Day (in which refugees' families can be involved in planning and development should they wish to do so), and ensuring the sporting activities are deliberately inclusive of newly arrived students and their families (e.g., by facilitating transport, or ensuring that information is translated so that families can be included).

Taken together, our research indicates the students in the study generally showed high levels of school belonging in most areas, but that this was frequently facilitated by the specific policies of the IELC they were in. This was seen through the focus on global issues, including awareness of the situation of refugees (as seen in the posters) and in strong relationships with teaching staff at the school. The study showed that by reflecting the identities of newly arrived students (at least to a degree), the students were able to build on what the school offered to create their own spaces in the broader school community. In this sense, it would appear that the IELCs were able 


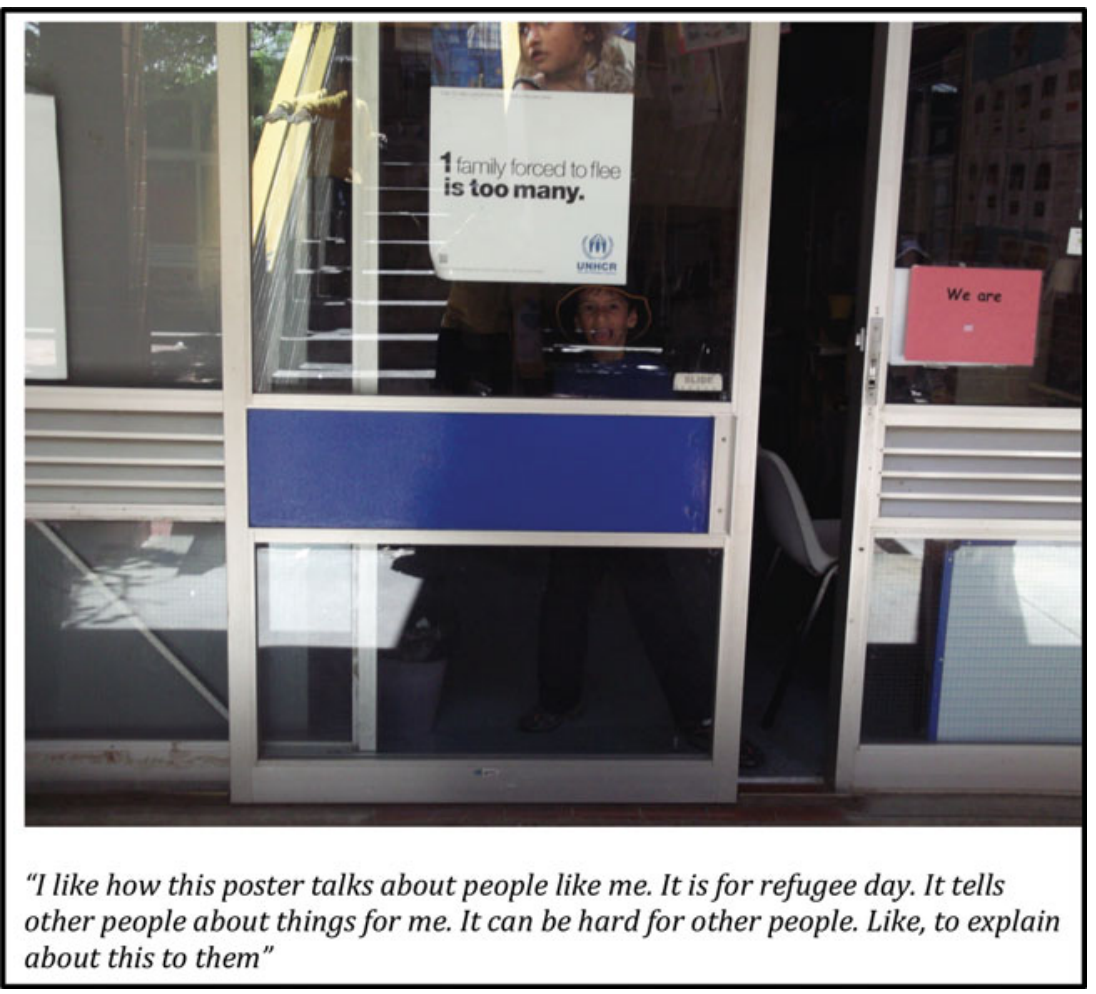

FIGURE 11

A UNHCR poster on the door to a library.

to successfully open up a two-way dialogue with refugee students to promote their sense of belonging. Within this space, then, the students themselves were able to develop relationships and make meaning in the school in order to form attachments. The question remains as to whether such positive experiences of school belonging continue after students have left their IELC and transitioned into mainstream schools where such initiatives and staff training may not be present. This is a useful area for future research.

It is important to note that this study was not without its limitations. In particular, the study included a focus on only three schools with a total of 15 participants. Given the diverse nature of refugee experiences, the study may not represent the experiences of all students in all IELCs, particularly those which are further from the city centre or have higher numbers of refugee students. In addition, the IELCs themselves are specific to South Australia, and in this sense, the findings may not extend to other intensive English language programs. Furthermore, and as seen perhaps specifically in the domain of commitment, the methodology of photo elicitation may have provided some limited data concerning school belonging. Nevertheless, the study highlights some important aspects of school belonging for young, newly arrived students with refugee backgrounds - and does so on their own terms. The findings highlight the importance of ensuring that schools develop activities that are of interest to students with refugee backgrounds and that reflect their skills, identities, and values. If they do 


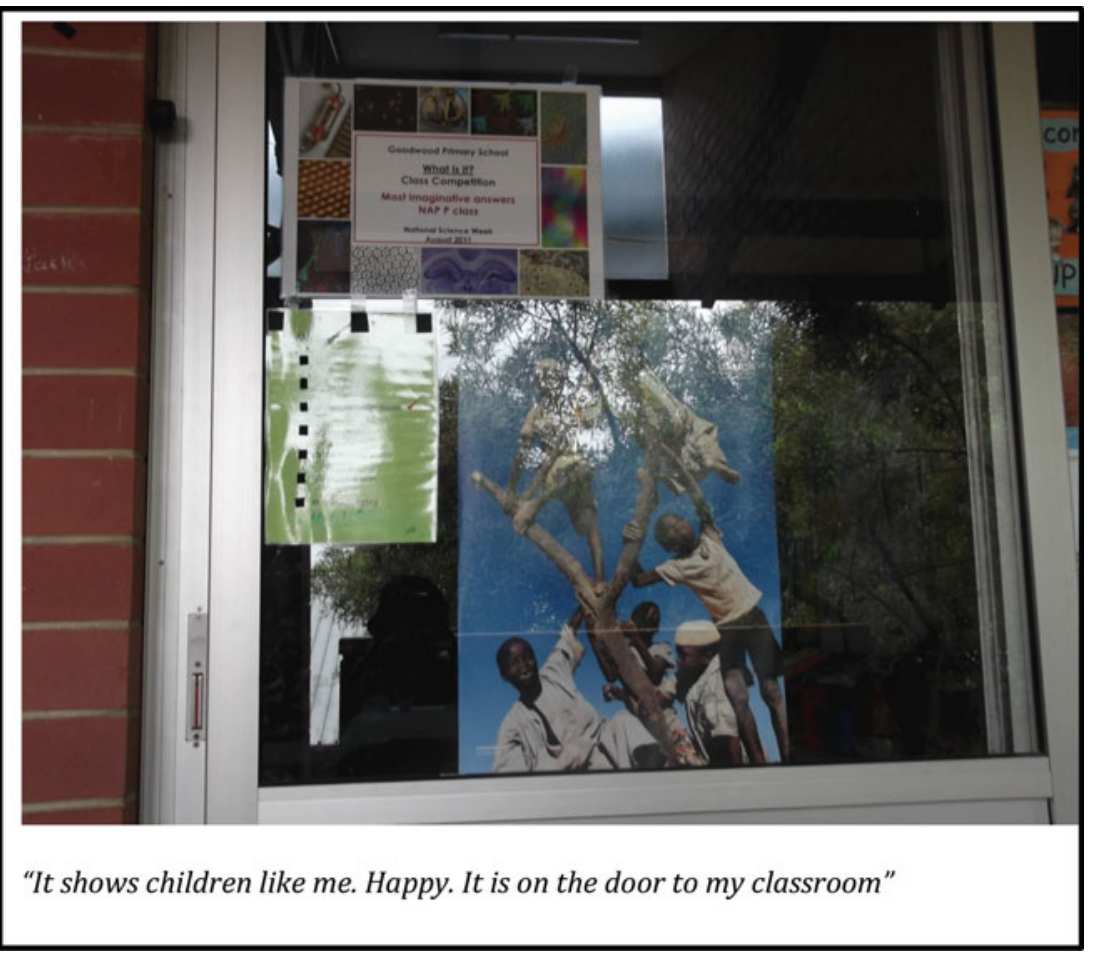

FIGURE 12

A World Refugee Day poster on the door to a classroom.

so, our findings suggest that newly arrived refugees will find spaces and relationships within the school through which to form a sense of belonging in their new community.

\section{Acknowledgments}

We would like to acknowledge all the children and schools who participated in this research. We could not have done it without them, and we are very grateful for their generosity in participating. We would also like to acknowledge the Australian Research Council for funding the research.

\section{Financial Support}

This research was funded by the Australian Research Council (grant number DP110100732)

\section{Conflicts of Interest}

\section{None}




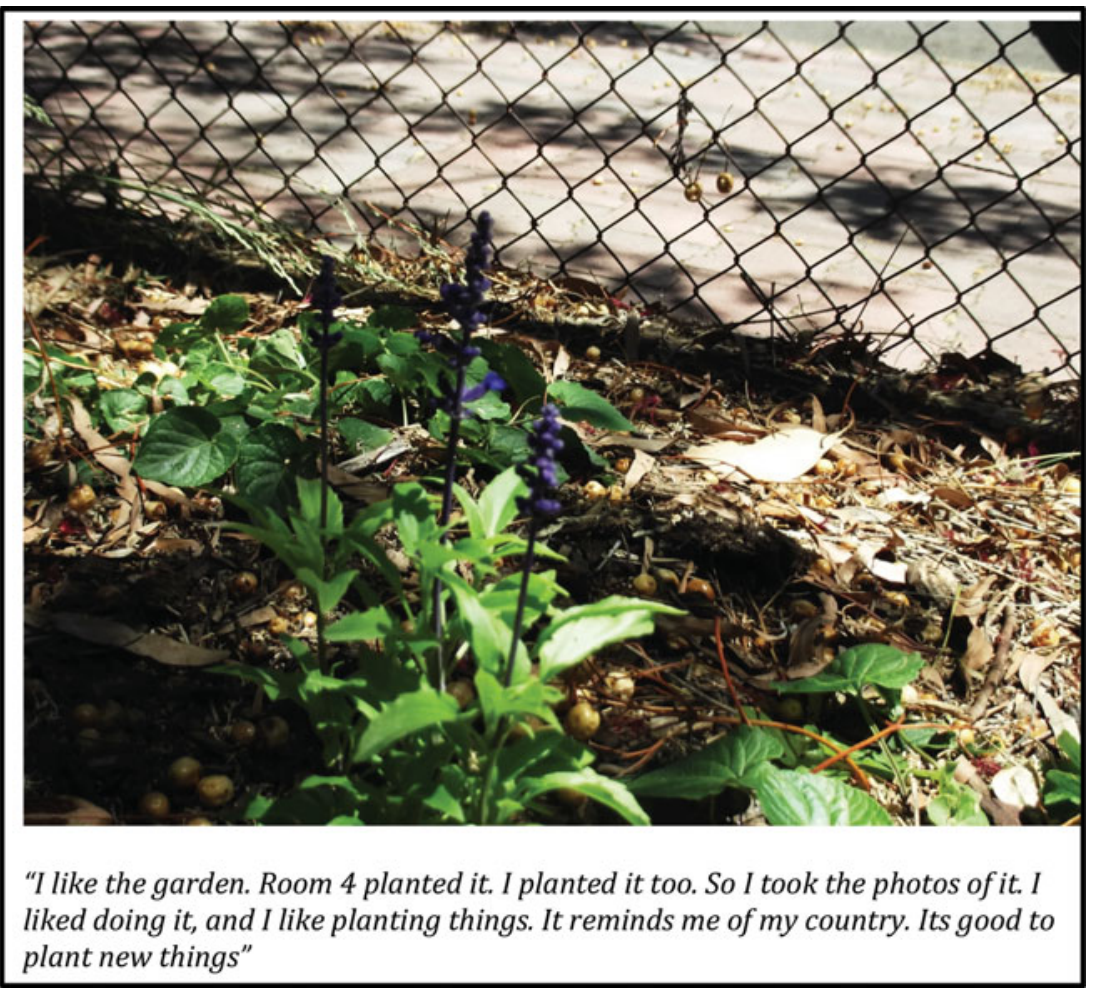

FIGURE 13

A flower planted during a gardening activity.

\section{Ethical Standards}

The authors assert that all procedures contributing to this work comply with the ethical standards of the relevant national and institutional committees on human experimentation and with the Helsinki Declaration of 1975, as revised in 2008

\section{References}

Anderman, E.M. (2002). School effects on psychological outcomes during adolescence. Journal of Educational Psychology, 94, 795-809. doi:10.1037//0022-0663.94.4.795

Battistich, V., Solomon, D., Watson, M., \& Schaps, E. (1997). Caring school communities. Educational Psychologist, 32, 137-151.

Baumeister, R.F., \& Leary, M.R. (1995). The need to belong: Desire for interpersonal attachments as a fundamental human motivation. Psychological Bulletin, 117, 497-529.

Block, K., Cross, S., Riggs, E., \& Gibbs, L. (2014). Supporting schools to create an inclusive environment for refugee students. International Journal of Inclusive Education, 18, 1337-1355. doi:10.1080/13603116.2014.899636

Braun, V., \& Clarke, V. (2013). Successful qualitative research: A practical guide for beginnners. London: Sage Publications.

Brown, C.S., \& Chu, H. (2012). Discrimination, ethnic identity and academic outcomes of Mexican immigrant children: The importance of school context. Child Development, 83, 1477-1485. doi:10.1111/j.1467-8624.2012.01786.x 
Correa-Velez, I., Gifford, S., \& Barnett, A. (2010). Longing to belong: Social inclusion and wellbeing among youth with refugee backgrounds in the first three years in Melbourne, Australia. Social Science and Medicine, 71, 1399-1408. doi:10.1016/j.socscimed.2010.07.018

Crivello, G., Camfield, L., \& Woodhead, M. (2009). How can children tell us about their wellbeing? Exploring the potential of participatory research approaches within Young Lives. Social Indicators Research, 90, 51-72. doi:10.1007/s11205-008-9312-x

Crouch, R., Keys, C.B., \& McMahon, S. (2014). Student-teacher relationships matter for school inclusion: School belonging, disability, and school transitions. Journal of Prevention and Intervention in the Community, 42, 20-30. doi:10.1080/10852352.2014.855054

Darbyshire, P., MacDougall, C., \& Schiller, W. (2005). Multiple methods in qualitative research with children: More research or just more? Qualitative Research, 5, 417-436. doi:10.1177/1468794105056921

de Heer, N., Due, C., \& Riggs, D.W. (2016). 'It will be hard because I will have to learn lots of English': Experiences of education for children with migrant backgrounds in Australia. The International Journal of Qualitative Studies in Education, 29, 297-319. doi:10.1080/09518398.2015.1023232

Department for Education and Child Development. (2012). Effective transition. Adelaide, Australia: Author. Retrieved from www.decd.sa.gov.au/literacy/files/links/Effective_Transition.pdf

Due, C., Riggs, D.W., \& Augoustinos, M. (2014). Research with children of migrant and refugee background: A review of child-centered research. Child Indicators Research, 7, 209-227. doi:10.1007/s12187-013-9214-6

Due, C., \& Riggs, D.W. (2011). Freedom to roam? Space use in primary schools with new arrivals programs. Online Journal of International Research in Early Childhood Education, 2, 1-16. Retrieved from http://arrow.monash.edu.au/hdl/1959.1/1048518

Ehntholt, K., \& Yule, W. (2006). Practitioner review: Assessment and treatment of refugee children and adolescents who have experienced war-related trauma. Journal of Child Psychology and Psychiatry, 47, 1197-1210. doi:10.1111/j.1469-7610.2006.01638.x

Fazel, M., Reed, R.V., Panter-Brick, C., \& Stein, A. (2012). Mental health of displaced and refugee children resettled in high-income countries: Risk and protective factors. The Lancet, 379, 266-282. doi:http://dx.doi.org/10.1016/S0140-6736(11)60051-2

Gifford, S., Bakopanos, C., Kaplan, I., \& Correa-Velez, I. (2007). Meaning or measurement? Researching the social contexts of health and settlement among newly-arrived refugee youth in Melbourne, Australia. Journal of Refugee Studies, 20, 414-440. doi:10.1093/jrs/fem004

Gifford, S., Correa-Velez, I., \& Sampson, R. (2009). Good starts for recently arrived youth with refugee backgrounds: Promoting wellbeing in the first three years of settlement in Melbourne, Australia. Melbourne, Australia: Refugee Health Research Centre \& Victorian Foundation for Survivors of Torture.

Goodenow, C. (1993). Classroom belonging among early adolescent students: Relationships to motivation and achievement. Journal of Early Adolescence, 13, 21-43.

Kia-Keating, M., \& Ellis, B.H. (2007). Belonging and connection to school in resettlement: Young refugees, school belonging and psychosocial adjustment. Clinical Child Psychology and Psychiatry, 12, 29-43. doi:10.1177/1359104507071052

Keddie, A. (2012). Refugee education and justice issues of representation, redistribution and recognition. Cambridge Journal of Education, 42, 197-212. doi:10.1080/0305764X.2012.676624

Mace, A.O., Mulheron, S., Jones, C., \& Cherian, S. (2014). Educational, developmental and psychological outcomes of resettled refugee children in Western Australia: A review of School of Special Educational Needs: Medical and Mental Health input. Journal of Paediatrics and Child Health, 50, 985-992. doi:10.1111/jpc.12674

Matthews, J. (2008). Schooling and settlement: Refugee education in Australia. International Studies in Sociology of Education, 18, 31-45. doi:10.1080/09620210802195947

McNeely, C., Nonnemaker, J., \& Blum, R. (2002). Promoting school connectedness: Evidence from the National Longitudinal Study of Adolescent Health. The Journal of School Health, 72, 138-146. doi:10.1111/j.1746-1561.2002.tb06533.x 
Newman, M., Woodcock, A., \& Dunham, P. (2006). 'Playtime in the borderlands': Children's representations of school, gender and bullying through photographs and interviews. Children's Geographies, 4, 289-302. doi:10.1080/14733280601005617

Olliff, L., \& Couch, J. (2005). Pathways and pitfalls: The journey of refugee young people in and around the education system in Greater Dandenong, Victoria. Youth Studies Australia, 24, 42-46.

Priest, N., Walton, J., White, F., Kowal, E., Baker, A., \& Paradies, Y. (2014). Understanding the complexities of ethnic-racial socialization processes for minority and majority groups: A 30-year systematic review. International Journal of Intercultural Relations, 43, 139-155. doi:10.1016/j.ijintrel.2014.08.003

Pugh, K., Every, D., \& Hattam, R. (2012). Inclusive education for students with refugee experience: Whole school reform in a South Australian primary school. The Australian Educational Researcher, 39, 125-141. doi:10.1007/s13384-011-0048-2

Riggs, D.W., \& Due, C. (2011). (Un)common ground?: English language acquisition and experiences of exclusion amongst new arrival students in Australian primary schools. Identities: Global Studies in Culture and Power, 18, 273-290. doi:10.1080/1070289X.2011.635373

Rousseau, C., Drapeau, A., \& Platt, R. (2004). Family environment and emotional and behavioural symptoms in adolescent Cambodian refugees: Influence of time, gender, and acculturation. Medicine, Conflict and Survival, 20, 151-65. doi:10.1080/1362369042000234735

Shochet, I.M., \& Smith, C.L. (2014). A prospective study investigating the links among classroom environment, school connectedness, and depressive symptoms in adolescents. Psychology in the Schools, 51, 480-492. doi:10.1002/pits

Sujoldzic, A., Peternel, L., Kulenovic, T., \& Terzic, R. (2006). Social determinants of health: A comparative study of Bosnian adolescents in different cultural contexts. Collegium Antropologicum, 30, 703-711.

Taylor, S., \& Sidhu, R.K. (2012). Supporting refugee students in schools: What constitutes inclusive education?. International Journal of Inclusive Education, 16, 39-56. doi:10.1080/13603110903560085

Trickett, E.J., \& Birman, N. (2005). Acculturation, school context, and school outcomes: Adaptation of refugee adolescents from the former Soviet Union. Psychology in the Schools, 42, 27-39. doi:10.1002/pits.20024

United National High Commissioner for Refugees (UNHCR). (2015). Worldwide displacement hits all time high as was and persecution increase. Retrieved from http://www.unhcr.org/558193896.html

Van Ryzin, M., Gravely, A., \& Roseth, C. (2009). Autonomy, belongingness, and engagement in school as contributors to adolescent psychological well-being. Journal of Youth and Adolescence, 38, 1-12. doi:10.1007/s10964-007-9257-4

Wehlage, G.G., Rutter, R.A., Smith, G.A., Lesko, N., \& Fernandez, R.R. (1989). Reducing the risk: Schools as communities of support. Philadelphia: Falmer.

Woods, A. (2009). Learning to be literate: Issues of pedagogy for recently arrived refugee youth in Australia. Critical Inquiry in Language Studies, 6, 81-101. doi:10.1080/15427580802679468 